\title{
INÍCIO DA CARREIRA DO PROFESSOR DE EDUCAÇÃO FÍSICA: UMA REVISÃO SISTEMÁTICA
}

\author{
Adair João Rachadel Arouca \\ Universidade do Estado de Santa Catarina, Florianópolis, Santa Catarina, Brasil. \\ Marcos Paulo Vaz de Campos Pereira \\ Universidade Federal de Pelotas, Pelotas, Rio Grande do Sul, Brasil \\ Marilia Pinto Garcia \\ Fundação Catarinense de Educação Especial, São José, Santa Catarina, Brasil. \\ Alzira Isabel da Rosa \\ Prefeitura Municipal de São José, São José, Santa Catarina, Brasil. \\ Gelcemar Oliveira Farias \\ Universidade do Estado de Santa Catarina, Florianópolis, Santa Catarina, Brasil.
}

\begin{abstract}
Resumo
Este estudo tem como objetivo analisar, na área da Educação Física, a produção científica sobre professores iniciantes na carreira docente. As bases de dados selecionadas foram Lilacs, SciELO, Ebsco, Scopus e Web of Knowledge. Os resultados indicam que os estudos encontrados foram publicados a partir de 2010, com concentração na região Sul do Brasil, tendo como foco a análise da prática pedagógica, o fazer cotidiano, a qualidade de vida dos professores. Tais investigações são predominantemente qualitativas, utilizando, para a coleta de dados, questionário e entrevistas. Conclui-se existir a necessidade de a comunidade científica direcionar suas investigações para esse tema, associando diferentes realidades e suas variáveis.
\end{abstract}

Palavras-chave: Mobilidade ocupacional. Docentes. Educação Física e treinamento. Revisão.

\section{CAREER START OF PHYSICAL EDUCATION TEACHER: A SYSTEMATIC REVIEW}

\begin{abstract}
This study aims to analyze, in the area of Physical Education, the scientific production on beginner teachers in the teaching career. The selected databases were LILACS, SCIELO, EBSCO, SCOPUS and WEB OF KNOWLEDGE. The results indicate that the studies found were published as of 2010, with a focus on the southern region of Brazil, focusing on the analysis of the pedagogical practice, the daily practice and the quality of life of the teachers. These investigations are predominantly qualitative, utilizing, for data collection, questionnaire and interviews. It is concluded that there is a need for the scientific community to direct their research to this theme, associating different realities and their variables.
\end{abstract}

Keywords: Career mobility. Faculty. Physical Education and Training. Review. 


\title{
CARRERA DE INICIO PROFESOR DE EDUCACIÓN FÍSICA: UNA REVISIÓN SISTEMÁTICA
}

\begin{abstract}
Resumen
Este estudio tiene como objetivo analizar en el área de la Educación Física, la producción científica sobre profesores principiantes en la carrera docente. Las bases de datos seleccionadas fueron LILACS, SciELO, EBSCO, SCOPUS y Web of Knowledge. Los resultados indicaron que los estudios encontrados son a partir de 2010, se concentró en el sur de Brasil, se centra en el análisis de la práctica pedagógica, hacen em los días, así como la calidad de vida. Estas investigaciones son predominantemente cualitativas, utilizando, para la recolección de datos, el cuestionario y las entrevistas. Se concluye que existe la necesidad de que la comunidad científica dirija sus investigaciones para este tema, asociando diferentes realidades y sus variables.
\end{abstract}

Palabras clave: Movilidad laboral. Docentes. Educación y Entrenamiento Físico. Revisión.

\section{Introdução}

Estudos centrados no início da carreira docente têm revelado que nesse período, correspondente aos primeiros anos de intervenção, ocorre a transição entre o ser discente e o ser docente, configurando-se como tempo de aprendizagem, no qual o professor se depara com novas situações (FARIAS; NASCIMENTO, 2012). Investigações sobre o tema, realizadas com docentes que atuam em escolas, evidenciam tanto a relação do tema investigado com identidade, bem-estar no contexto de trabalho, socialização profissional, como com dilemas e desafios a serem superados pelos docentes (FREITAS, 2002; BOTH, 2016; FARIAS et al., 2016; ILHA; KRUG, 2016). Estudos específicos com os docentes que atuam no ensino superior ainda carecem de ampliação (FREIRE; FERNANDEZ, 2015).

$\mathrm{O}$ início da carreira mostra-se como o período de aquisição de conhecimentos profissionais e de constantes aprendizagens sobre o exercício profissional (GARCIA, 1999; GABARDO; HOBOLD, 2011). Ele constitui-se em uma etapa de desafios, tensões, desequilíbrios e reorganização das expectativas quanto à sua ocupação no universo profissional (CAVACO, 1991; ILHA; KRUG, 2016), sendo considerado como um tempo de evolução pessoal e social, visto as escassas experiências anteriores em trabalho de magistério.

A complexidade da carreira docente é composta por distintas fases, pelas quais o professor passa no decorrer de seu exercício profissional. Investigações centradas na carreira de professores buscaram compreender os fatores associados à vida profissional desde os primeiros contatos com a docência até o abandono ou a aposentadoria, tendo sido a docência classificada em ciclos, etapas ou estágios (HUBERMAN, 2000; GONÇALVES, 2000; 2009; STEFFY et al., 2000; FARIAS; NASCIMENTO, 2012), considerando os processos evolutivos a ela inerentes.

O foco do presente estudo concentra-se em professores novatos de Educação Física, aqueles que, embora a pouca ou restrita experiência em docência, atuam na profissão e ocupam cargos escolares. Na literatura, os estudos relacionados a professores de Educação Física são incipientes. Em geral, eles investigam o início da carreira sem desconsiderar os demais ciclos, fases ou estágios de desenvolvimento profissional (FARIAS; NASCIMENTO, 2012; MARTINS, 2016), ou seja, os estudos tendem a analisar a dimensão macro da carreira. Todavia, essa etapa preliminar de atuação, rica em aprendizagens, requer estudos mais amplos, a fim de serem dimensionadas situações reais que nela ocorrem. 
$\mathrm{Na}$ formação inicial, é relevante ampliar os conhecimentos dos futuros professores sobre a realidade a ser vivida nos primeiros anos da carreira, de modo a amenizar as situações detectadas por Hubermam (2000) no estágio de sobrevivência, quando o docente se depara com a realidade da intervenção a qual se apresenta distanciada do que foi idealizado. A Resolução 02/2015 estabelece que a formação inicial deve reconhecer a especificidade do trabalho docente, de modo que o egresso tenha conhecimento sobre dinâmicas educativas, tecnologia de informação e comunicação e demais ações pertinentes ao exercício do magistério (BRASIL, 2015).

Alves (2001) explica que o futuro professor vai encontrar, em seu caminho, uma realidade incerta, com variadas e distintas circunstâncias, tais como ministrar aulas para determinada quantidade de alunos, atender estudantes de diferentes idades, atuar em lugares diversos. Na medida do possível, tais circunstâncias devem ser previstas no curso de formação, a fim de instrumentalizar o professor com alternativas para solucionar as dificuldades.

Estudos centrados no princípio da carreira buscam compreender tanto a identidade profissional, mediada pelas primeiras experiências profissionais e por aquelas vivenciadas na formação inicial (FARIAS et al. 2016), como fatores relacionados ao bem-estar docente, à socialização profissional e aos desafios que norteiam essa etapa da carreira docente (ILHA; KRUG, 2016; BOTH, 2016). Essa fase de transição entre a formação e a adequação ao mercado de trabalho representa o encontro com a docência, o que Wittizorecki e Frasson (2016) descrevem como um "momento de inscrição na cultura escolar e nas pautas do trabalho docente" (p. 240).

No presente estudo, analisou-se a produção científica na área da Educação Física sobre professores iniciantes na carreira docente. Compreender o que tem sido produzido na área é relevante, pois possibilita discernir as ideias que os autores têm divulgado à comunidade científica, no contexto da realidade brasileira. É proeminente também entender como o professor de Educação Física age e organiza sua prática pedagógica nos primeiros anos de atuação e exercício profissional.

\section{Método}

O estudo caracteriza-se como uma revisão sistemática, baseada em estudos primários (SCHÜTZ; SANT'ANA; SANTOS, 2011), ou seja, é um estudo que utiliza investigações publicadas na literatura sobre o tema em questão (SAMPAIO; MANCINI, 2007). Para a sistematização, seguiram-se as orientações estabelecidas por Saur-Amaral (2011), que, preliminarmente, solicita a organização do estudo mediante uma ficha de pesquisa que contemple objetivo da pesquisa, equações de pesquisa a experimentar, âmbito da pesquisa, critérios de inclusão, critérios de exclusão, critérios de qualidade e validade metodológica, filtragem de resultados e resultados da pesquisa. Elaborada essa ficha, pode-se iniciar a coleta de dados.

Para a busca das informações, foram selecionadas as seguintes bases de dados: Lilacs, Scielo, Ebsco, Scopus e Web of Knowledge. Elas foram escolhidas por se considerar que são as que apresentam o maior número de periódicos indexados e contemplam os estudos relacionados à formação e à intervenção de professores no início da carreira no contexto educacional.

De modo a atender o objetivo do estudo, foram utilizados os descritores: início da carreira and Educação Física, professor iniciante and Educação Física, início da docência and Educação Física, docente and início da carreira and Educação Física, Educação Física and carreira. A coleta de dados nas bases de dados selecionadas respeitou os seguintes critérios de inclusão: artigos nacionais publicados em língua portuguesa; artigos que atendem aos 
descritores do estudo; artigos que contemplem a área da Educação Física, publicados na integra, a partir de 1990. Consideraram-se como critérios de exclusão: artigos sem abstract ou sem texto integral; artigos não relacionados com o tema em causa ou publicados em revistas fora do âmbito do assunto mencionado; artigos escritos em espanhol ou inglês ou publicados antes de 1990.

A coleta de dados foi realizada em dois momentos distintos, de modo a verificar a ampliação das publicações referentes à temática de investigação. A primeira coleta nas bases selecionadas foi realizada em dezembro de 2014, sendo replicada em março de 2015, utilizando os mesmos critérios. Da primeira para a segunda etapa, houve o acréscimo de dois estudos. Esse aumento ocorreu pelo fato de, entre dezembro de 2014 e março de 2015, terem sido publicados novos números e volumes dos periódicos e, em consequência, na reprodução da busca, foram encontrados novos estudos que atendiam aos critérios de inclusão.

Após a leitura do título, do resumo e do texto completo de cada artigo, refinou-se o processo de coleta de dados e selecionaram-se somente os estudos que atendiam aos critérios de inclusão. Nessa etapa, encontraram-se, inicialmente, 17 estudos, sendo 13 na base Scielo, dois na base Lilacs e dois na base Web of Knowledge (Tabela 1). Na segunda fase de coleta, houve ampliação das publicações, resultando em um total de 19 estudos, pois foram encontrados dois estudos adicionais na base Scielo (Tabela 2).

Embora tenham sido realizadas duas coletas de dados, com o intuito de ampliar o repertório de análise, os estudos que foram coletados na segunda coleta de dados e que poderiam ser destacados, ao se aplicar os critérios de inclusão, foram eliminados.

Tabela 1 - Levantamento dos estudos encontrados nas bases de indexação selecionadas - $1^{\mathrm{a}}$ etapa.

\begin{tabular}{|c|c|c|c|c|c|}
\hline \multirow{3}{*}{ Base de dados } & \multirow{3}{*}{$\begin{array}{c}\text { Procura } \\
\text { inicial }\end{array}$} & \multicolumn{4}{|c|}{ Refinamento } \\
\hline & & \multirow{2}{*}{$\begin{array}{c}\text { Seleção } \\
\text { automática }\end{array}$} & \multicolumn{3}{|c|}{ Seleção manual } \\
\hline & & & Duplicados & Abstract & Texto completo \\
\hline SCIELO & 13 & 6 & 2 & 6 & 6 \\
\hline WEB OF KNOWLEDGE & 2 & 1 & 1 & 0 & 0 \\
\hline LILACS & 2 & 2 & 0 & 2 & 2 \\
\hline SCOPUS & 0 & 0 & 0 & 0 & 0 \\
\hline EBSCO & 0 & 0 & 0 & 0 & 0 \\
\hline Total & 17 & 9 & 3 & 8 & 8 \\
\hline
\end{tabular}

Fonte: Elaborada pelos autores, 2017.

Tabela 2 - Levantamento dos estudos encontrados nas bases de indexação selecionadas - $2^{\text {a }}$ etapa

\begin{tabular}{l|c|c|c|c|c}
\hline \multirow{2}{*}{\multicolumn{1}{c}{ Base de dados }} & \multirow{2}{*}{$\begin{array}{c}\text { Procura } \\
\text { inicial }\end{array}$} & \multirow{2}{*}{$\begin{array}{c}\text { Seleção } \\
\text { automática }\end{array}$} & \multicolumn{3}{c}{ Refinamento } \\
\cline { 3 - 6 } & & 6 & 2 & 6 & Seleção manual \\
\hline SCIELO & 15 & 1 & 1 & 0 & 0 \\
\hline WEB OF KNOWLEDGE & 2 & 2 & 0 & 2 & 2 \\
\hline LILACS & 2 & 0 & 0 & 0 & 0 \\
\hline SCOPUS & 0 & 0 & 0 & 0 & 0 \\
\hline EBSCO & 0 & $\mathbf{9}$ & $\mathbf{3}$ & $\mathbf{8}$ & $\mathbf{8}$ \\
\hline Total & $\mathbf{1 9}$ & & & & 0 \\
\hline
\end{tabular}

Fonte: Elaborada pelos autores, 2017.

Para a análise dos dados, os textos foram submetidos ao processo de análise de conteúdo, de acordo com as orientações de Bardin (1977). Após a leitura completa de todos os artigos, foram abertas categorias referentes a objetivos, método e resultados. Depois da exploração do material, foram abertas categorias a posteriori que possibilitaram compreender a relação entre os objetivos, o método e os resultados. Ademais, surgiram, em cada categoria, subcategorias especificadoras da categoria maior. 


\section{Resultados e discussão}

O período denominado início da docência refere-se à transição entre ser discente e ser docente, ou seja, corresponde aos primeiros anos de exercício profissional. Na perspectiva de Gabardo e Hobold (2011), essa etapa propicia ao docente aprendizagens intensas em contextos até então não conhecidos ou não vividos por ele. Ela é percebida como o tempo de aquisição de conhecimentos para a continuidade na profissão. Nesse momento, o docente depara-se com incertezas e desafios oriundos das situações cotidianas da escola (CONCEIÇÃO; MOLINA NETO, 2016). Em alguns casos, ele é impactado pelo choque com a realidade e, em outros, sente o entusiasmo pela docência (HUBERMAN, 2000).

$\mathrm{Na}$ análise pormenorizada dos textos lidos na íntegra (Quadro 1), encontraram-se oito estudos elegíveis, todos desenvolvidos no Brasil e publicados na área da Educação Física a partir de 1990 (GONÇALVES; SANTOS; MARTINS JÚNIOR, 2007; FOLLE et al., 2009; AMORIM FILHO; RAMOS, 2010; MOREIRA et al., 2010; FARIAS et al., 2011; FARIAS et al., 2012; ROSSI; HUNGER, 2012; BOTH et al., 2013). No início da carreira, refletem-se a dimensão de novos saberes, as constantes fragilidades, o conhecimento sobre as complexidades do ensino, o choque de realidade e o entusiasmo de ser docente (HUBERMAN, 2000; FARIAS; NASCIMENTO, 2012; ILHA; KRUG, 2016). Diferentemente, nas fases mais avançadas de desenvolvimento profissional, emerge o sentimento de pertencimento ao grupo de professores da escola, surge a segurança para a intervenção profissional e consolida-se o conhecimento sobre os fatores inerentes à profissão.

Quadro 1 - Estudos analisados sobre o início da carreira docente

\begin{tabular}{|c|c|c|c|c|}
\hline Autores & Título & Ano & Objetivo(s) & Metodologia \\
\hline $\begin{array}{l}\text { Mário Lucio de } \\
\text { Amorim Filho; } \\
\text { Glauco Nunes } \\
\text { Souto Ramos }\end{array}$ & $\begin{array}{l}\text { Trajetória de } \\
\text { vida e } \\
\text { construção dos } \\
\text { saberes de } \\
\text { professoras de } \\
\text { educação física }\end{array}$ & 2010 & $\begin{array}{l}\text { Analisar a trajetória de vida } \\
\text { de duas professoras de } \\
\text { educação física escolar dos } \\
\text { ensinos fundamental e médio } \\
\text { da rede pública da cidade de } \\
\text { São Carlos-SP. }\end{array}$ & $\begin{array}{l}\text { O estudo usou abordagem } \\
\text { qualitativa e teve como } \\
\text { instrumento de coleta de } \\
\text { dados uma entrevista } \\
\text { semiestruturada. }\end{array}$ \\
\hline $\begin{array}{l}\text { Gelcemar Oliveira } \\
\text { Farias; Juarez } \\
\text { Vieira do } \\
\text { Nascimento; } \\
\text { Amândio Graça; } \\
\text { Paula Maria } \\
\text { Fazendeiro Batista }\end{array}$ & $\begin{array}{l}\text { Competências } \\
\text { profissionais em } \\
\text { Educação } \\
\text { Física: uma } \\
\text { abordagem ao } \\
\text { longo da } \\
\text { carreira docente }\end{array}$ & 2012 & $\begin{array}{l}\text { Verificar as competências } \\
\text { profissionais elucidadas na } \\
\text { carreira docente de } \\
\text { professores de Educação } \\
\text { Física escolar. }\end{array}$ & $\begin{array}{c}\text { Na coleta de dados, utilizou- } \\
\text { se um questionário composto } \\
\text { por perguntas abertas e } \\
\text { fechadas. }\end{array}$ \\
\hline $\begin{array}{l}\text { Gelcemar Oliveira } \\
\text { Farias; Juarez } \\
\text { Vieira do } \\
\text { Nascimento; } \\
\text { Amândio Graça; } \\
\text { Paula Maria } \\
\text { Fazendeiro Batista }\end{array}$ & $\begin{array}{l}\text { Crenças e } \\
\text { expectativas } \\
\text { constituídas ao } \\
\text { longo da } \\
\text { carreira docente } \\
\text { em educação } \\
\text { física }\end{array}$ & 2011 & $\begin{array}{l}\text { Analisar as crenças, as } \\
\text { perspectivas e as } \\
\text { expectativas constituídas, ao } \\
\text { longo da carreira docente, } \\
\text { pelos professores de } \\
\text { Educação Física da rede } \\
\text { pública municipal de Porto } \\
\text { Alegre. }\end{array}$ & $\begin{array}{l}\text { Para a coleta dos dados, foi } \\
\text { utilizado um questionário, } \\
\text { composto de questões } \\
\text { abertas e fechadas. }\end{array}$ \\
\hline $\begin{array}{l}\text { Hudson de Resende } \\
\text { Moreira; Juarez } \\
\text { Vieira do } \\
\text { Nascimento; } \\
\text { Christi Noriko } \\
\text { Sonoo; Jorge Both }\end{array}$ & $\begin{array}{c}\text { Qualidade de } \\
\text { vida no trabalho } \\
\text { e perfil do estilo } \\
\text { de vida } \\
\text { individual de } \\
\text { professores de } \\
\text { Educação Física }\end{array}$ & 2010 & $\begin{array}{l}\text { Analisar a percepção de } \\
\text { Qualidade de Vida no } \\
\text { Trabalho, o Estilo de Vida e } \\
\text { suas associações com os } \\
\text { Ciclos de Desenvolvimento } \\
\text { Profissional dos professores } \\
\text { de Educação Física da rede }\end{array}$ & $\begin{array}{l}\text { O QVT-PEF (BOTH et al., } \\
\text { 2006) e o PEVI (NAHAS et } \\
\text { al., 2000) foram empregados } \\
\text { na coleta de dados. }\end{array}$ \\
\hline
\end{tabular}




\begin{tabular}{|c|c|c|c|c|}
\hline & $\begin{array}{c}\text { ao longo da } \\
\text { carreira docente }\end{array}$ & & estadual do Paraná. & \\
\hline $\begin{array}{l}\text { Fernanda Rossi; } \\
\text { Dagmar Hunger }\end{array}$ & $\begin{array}{l}\text { As etapas da } \\
\text { carreira docente } \\
\text { e o processo de } \\
\text { formação } \\
\text { continuada de } \\
\text { professores de } \\
\text { Educação Física }\end{array}$ & 2012 & $\begin{array}{l}\text { Analisar os significados } \\
\text { atribuídos por professores de } \\
\text { Educação Física escolar à } \\
\text { relação entre a formação } \\
\text { continuada e as etapas do } \\
\text { desenvolvimento } \\
\text { profissional. }\end{array}$ & $\begin{array}{l}\text { Tem caráter qualitativo. } \\
\text { Foram realizadas entrevistas } \\
\text { semiestruturadas com oito } \\
\text { professores da rede pública } \\
\text { estadual de Bauru/SP. }\end{array}$ \\
\hline $\begin{array}{l}\text { Jorge Both; Juarez } \\
\text { Vieira do } \\
\text { Nascimento; } \\
\text { Christi Noriko } \\
\text { Sonoo; Carlos } \\
\text { Augusto Fogliarini } \\
\text { Lemos; Adriano } \\
\text { Ferreti Borgatto }\end{array}$ & $\begin{array}{l}\text { Bem-estar do } \\
\text { trabalhador } \\
\text { docente em } \\
\text { Educação Física } \\
\text { ao longo da } \\
\text { carreira }\end{array}$ & 2013 & $\begin{array}{c}\text { Analisar o bem-estar do } \\
\text { trabalhador docente por meio } \\
\text { do parâmetro socioambiental } \\
\text { (satisfação no trabalho) e do } \\
\text { parâmetro individual (estilo } \\
\text { de vida) dos professores de } \\
\text { Educação Física, } \\
\text { considerando os ciclos de } \\
\text { desenvolvimento } \\
\text { profissional. }\end{array}$ & $\begin{array}{c}\text { Foi utilizado um } \\
\text { questionário } \\
\text { sociodemográfico e } \\
\text { profissional, bem como os } \\
\text { instrumentos QVT-PEF e } \\
\text { PEVI. }\end{array}$ \\
\hline $\begin{array}{c}\text { Alexandra Folle; } \\
\text { Gelcemar Farias; } \\
\text { Juliano Daniel } \\
\text { Boscatto; Juarez } \\
\text { Vieira do } \\
\text { Nascimento. }\end{array}$ & $\begin{array}{l}\text { Construção da } \\
\text { carreira docente } \\
\text { em Educação } \\
\text { Física: escolhas, } \\
\text { trajetórias e } \\
\text { perspectivas }\end{array}$ & 2009 & $\begin{array}{l}\text { Analisar a história de vida de } \\
\text { professores de Educação } \\
\text { Física, procurando identificar } \\
\text { as escolhas, as perspectivas e } \\
\text { as trajetórias vivenciadas. }\end{array}$ & $\begin{array}{l}\text { Na recolha das informações, } \\
\text { foi utilizada a entrevista } \\
\text { semiestruturada. A técnica } \\
\text { da narrativa foi empregada } \\
\text { na análise dos dados. }\end{array}$ \\
\hline $\begin{array}{l}\text { Elisiane Cristina de } \\
\text { Freitas Gonçalves; } \\
\text { Aline Elias de } \\
\text { Oliveira dos } \\
\text { Santos; José } \\
\text { Antonio Martins } \\
\text { Júnior }\end{array}$ & $\begin{array}{l}\text { Prática docente: } \\
\text { dificuldades } \\
\text { encontradas } \\
\text { pelos } \\
\text { professores de } \\
\text { Educação Física } \\
\text { nos cinco } \\
\text { primeiros anos } \\
\text { de atuação } \\
\text { profissional }\end{array}$ & 2007 & $\begin{array}{c}\text { Analisar e descrever as } \\
\text { dificuldades dos professores } \\
\text { de educação física nos cinco } \\
\text { primeiros anos de atuação } \\
\text { profissional, em relação à sua } \\
\text { prática pedagógica } \\
\text { desenvolvida nas escolas. }\end{array}$ & $\begin{array}{l}\text { A metodologia utilizada } \\
\text { contemplou o trabalho } \\
\text { de campo e a revisão de } \\
\text { literatura. Foi aplicado um } \\
\text { questionário elaborado por } \\
\text { Campos (2004) aos } \\
\text { professores que trabalham } \\
\text { com a disciplina Educação } \\
\text { Física, na educação básica } \\
\text { das escolas sede da rede } \\
\text { estadual de ensino de } \\
\text { Caratinga, MG. }\end{array}$ \\
\hline
\end{tabular}

Fonte: Elaborado pelos autores, 2017.

Tendo sido analisadas investigações publicadas desde 1990, verificou-se que a maior concentração de estudos sobre docentes em início de carreira ocorre a partir do ano de 2010. Quanto à região na qual os estudos foram desenvolvidos, cinco estudos situaram-se na região Sul do Brasil (FOLLE et al., 2009; MOREIRA et al., 2010; FARIAS et al., 2011; FARIAS et al., 2012; BOTH et al., 2013), sendo a de maior aglutinação, e três estudos foram desenvolvidos na região Sudeste (GONÇALVES; SANTOS; MARTINS JÚNIOR, 2007; AMORIM FILHO; RAMOS, 2010; ROSSI; HUNGER, 2012). Coutinho et al. (2012) evidenciam o crescente aumento de grupos de pesquisa e de programas de pós-graduação na área da Educação Física, a partir do ano 2000, especialmente, na região Sudeste no primeiro momento, seguindo-se as regiões Centro-Oeste e Sul do Brasil. Esse fato, de certa forma, contribui para o maior número de estudos encontrados nas regiões Sul e Sudeste.

Verifica-se haver relação entre a data de publicação dos oito estudos elegíveis e o crescimento de pesquisas e de grupos de pós-graduação, nos anos 2000, visto que o primeiro estudo data de 2007 e o mais recente, de 2013. A maior incidência de publicações na região Sul está associada à concentração de programas de pós-graduação na área da Educação Física, Educação e Ciência do Movimento Humano nela existente. Para Coutinho et al. (2012), o 
aumento das bases de produção científica da Educação Física destaca-se em todas as regiões do Brasil, porém as regiões Sul e Sudeste são os principais centros de produção de conhecimento. O estudo de Leite et al. (2012) mostra que o maior acúmulo de pesquisadores de produtividade do CNPQ encontra-se em universidades das regiões Sul e Sudeste do Brasil.

Ao analisar os objetivos dos artigos, percebe-se que são evidenciados os aspectos que influenciam a prática pedagógica do professor de Educação Física, abordando temas no seu fazer cotidiano, traduzindo-se em compreender os elementos constitutivos da carreira docente. O estudo de Farias et al. (2012) averiguou as competências profissionais elucidadas na carreira docente de professores de Educação Física escolar. Os estudos de Moreira et al. (2010) e Both et al. (2013) centraram-se na análise da qualidade de vida de professores de Educação Física, bem como no estilo de vida e na satisfação no trabalho docente, relacionados com o desenvolvimento profissional.

A trajetória de vida profissional foi evidenciada nos estudos de Folle et al. (2009) e de Amorim Filho e Ramos (2010), no que se refere tanto à relação entre a trajetória de vida dos professores escolares novatos e dos experientes quanto à identificação de escolhas, perspectivas e trajetórias vivenciadas. As investigações de Farias et al. (2011) e Rossi e Hunger (2012) analisaram não só o desenvolvimento profissional docente nos diferentes ciclos, identificando crenças, perspectivas e expectativas, como também o significado da formação continuada durante a atuação docente. O estudo de Gonçalves, Santos e Martins Junior (2007) foi o único que investigou professores em fase inicial da carreira, com a intenção de analisar e descrever as dificuldades dos professores de Educação Física em seus primeiros contatos com a docência.

Existe uma preocupação dos pesquisadores quanto à compreensão da atuação docente e do desenvolvimento profissional em Educação Física. Todavia, embora exista essa inquietação, as investigações publicadas por pesquisadores brasileiros ainda são escassas, pois se apresentam em número reduzido e limitado, requerendo sua ampliação e um olhar dirigido a outros fatores como preocupações docentes, processos didáticos, ansiedade, dificuldades da carreira.

Ademais, tornam-se imperativos estudos voltados aos professores na fase inicial, com foco na análise e no conhecimento dessa etapa crucial da carreira, bem como pesquisas que questionem seus anseios e suas indiferenças (MARCON; NASCIMENTO;GRAÇA; 2013). As fragilidades na formação inicial também carecem de estudos, a fim de se estabelecer a complexidade da fase primeira da carreira e os períodos de aprendizagem antes e durante a docência (GONÇALVES; SANTOS; MARTINS JÚNIOR, 2007; FOLLE et al., 2009; GABARDO; HOBOLD; 2011).

No que se refere aos métodos aplicados nas pesquisas relatadas nos artigos encontrados, foram diagnosticados estudos com abordagem qualitativa (GONÇALVES; SANTOS; MARTINS JÚNIOR, 2007; FOLLE et al., 2009; AMORIM FILHO; RAMOS, 2010; FARIAS et al., 2011; FARIAS et al., 2012; ROSSI; HUNGER, 2012) e estudos com abordagem quantitativa (MOREIRA et al., 2010; BOTH et al., 2013). A maior quantidade concentra-se nos estudos qualitativos, coincidindo com a abordagem mais utilizada pelos autores que investigam o início da carreira docente.

As pesquisas com abordagem qualitativa procuram, por meio do contexto investigado, estudar os sujeitos, suas ações, seus valores e suas crenças. Os estudos com abordagem qualitativa buscam investigar essas situações com um cunho revelador. Os dados não são mensuráveis, mas se mostram fundamentais para a análise dos resultados da pesquisa e para evidenciar, através do sujeito, o fenômeno investigado (SILVA; VELOZO; RODRIGUES JUNIOR, 2008; NEGRINI, 2010; SANTOS; MORETTI-PIRES, 2012).

Como população investigada, predominaram os professores de Educação Física, considerando-se sua diferenciação quanto ao tempo da carreira. $\mathrm{O}$ estudo de Folle et al. 
(2009) avaliou professores no final da carreira docente e destacou suas experiências profissionais no início da carreira. O estudo de Gonçalves, Santos e Martins Júnior (2007) averiguou professores durante seus primeiros contatos com a escola.

Os demais estudos (AMORIM FILHO; RAMOS, 2010; MOREIRA et al., 2010; FARIAS et al., 2011; FARIAS et al., 2012; ROSSI; HUNGER, 2012; BOTH et al., 2013) investigaram professores em distintos períodos da carreira docente. Rossi e Hunger (2012) alocaram os professores em três períodos: estabilização (quatro a seis anos de carreira); diversificação ou questionamentos (sete a 25 anos de carreira); serenidade e distanciamento (25 a 35 anos de carreira).

Independente do tempo da carreira do professor de Educação Física, todos passaram por um início, alguns com mais tranquilidade, outros com experiências que deixaram marcas persistentes no decorrer de sua intervenção. Marcon, Nascimento e Graça (2013) sugerem a valorização, na formação inicial, do conhecimento do contexto pedagógico, através de situações e estratégias didáticas e pedagógicas, tais como as práticas como componente curricular. Os futuros professores obteriam assim a compreensão de fatores preponderantes no exercício profissional, entre os quais se destacam a dimensão dos conteúdos e a relação entre aluno e escola. Haveria também estímulo à reflexão e ao desenvolvimento do senso crítico dos estudantes, minimizando impactos decorrentes do começo da intervenção.

Em relação aos instrumentos de coleta de dados, os questionários e as entrevistas foram utilizados pelos autores quer de forma individual, quer associando os dois instrumentos na recolha das informações. Fizeram uso de questionários as investigações de Gonçalves, Santos e Martins Júnior (2007), Moreira et al. (2010), Farias et al. (2011), Farias et al. (2012), Both et al. (2013). Utilizaram-se de entrevistas semiestruturadas: Folle et al. (2009), Amorim Filho e Ramos (2010), Rossi e Hunger (2012). Contudo, Negrini (2010) pondera ser a observação o instrumento de coleta de dados mais utilizado em estudos qualitativos.

Quanto aos resultados dos estudos, a qualidade e o estilo de vida de professores no início da carreira foram investigados por Moreira et al. (2010). Eles concluíram que a maior insatisfação dos professores durante sua carreira advém, dentre outros argumentos, da má remuneração, da falta de compensação, das condições de trabalho, da integração social no ambiente de trabalho, já evidenciado pelos professores iniciantes. Esse dado é semelhante aos achados do estudo de Both et al. (2013), no qual foram incluídos comportamentos negativos relacionados à alimentação, ao controle de estresse e à atividade física. Ambos os estudos identificaram comportamentos positivos quanto à qualidade e ao estilo de vida e à satisfação com o trabalho, compondo um resultado positivo sobre a avaliação global do bem-estar do trabalhador docente.

Os autores que focaram a trajetória e a carreira do professor de Educação Física identificaram possíveis influências correspondentes à infância do docente. Segundo Amorim Filho e Ramos (2010), os dados evidenciaram a ideia do trabalho sistematizado e de atitudes severas, reflexos de uma educação rígida e dos valores transmitidos pelos pais, no caso de professores mais antigos.

Os professores mais novos demonstram, em alguns momentos, descontentamento com a Educação Física, talvez pela frustração de não conseguirem praticar alguma modalidade esportiva. Isso é confirmado por Folle et al. (2009), ao exporem que as especificidades da história de vida pessoal de cada professor influenciam a abordagem adotada em suas aulas. É reforçada também a necessidade de realização de mais estudos sobre crenças, valores, competências, dentre outros aspectos, visando auxiliar na sistematização dos anos de docência no desenvolvimento profissional de professores de Educação Física.

A individualidade de cada professor imprime a própria identidade em suas experiências quer como atleta, quer como estudante tanto da educação básica quanto da formação inicial. Os tempos da formação promovem aprendizagens que se tornam exercício 
para a docência, sendo referenciadas na entrada na carreira. Elas mobilizam crenças que permitem ao docente construir e reconstruir sua identidade; dimensionar desafios, enfrentamentos e apegos trazidos da vida acadêmica; controlar a insegurança nos enfrentamentos com a realidade escolar; administrar situações como a do pluriemprego (FARIAS; NASCIMENTO, 2012; CONCEIÇÃO; MOLINA NETO, 2016; FARIAS et al. 2016).

Farias et al. (2011) investigaram as crenças e as expectativas do profissional de Educação Física escolar, evidenciando a existência de diferenciação em relação ao gênero. As professoras centram-se em status profissional, formação do aluno, inovações na proposta e melhoria do ensino e os professores olham para aquisição de prestígio profissional e melhoria do salário. Perceberam também que, nos professores iniciantes, as expectativas profissionais superam as expectativas pessoais. Gonçalves, Santos e Martins Júnior (2007) focaram as dificuldades surgidas nos cinco primeiros anos de atuação do professor de Educação Física em relação à sua prática pedagógica. Eles encontraram dificuldades semelhantes às descritas em estudos anteriores.

Confirmando o que Rossi e Hunger (2012) expuseram sobre a entrada na carreira (os primeiros anos da carreira do docente), Farias et al. (2012) mostram evidências que determinam a evolução das competências dos professores durante sua intervenção e sua carreira. Destacam que, no início, tal evolução ocorre de maneira mais tímida - talvez por isso surjam dificuldades -, destacando-se só no período de dez a 30 anos de docência.

A atuação docente no início de carreira, conforme Marcon, Nascimento e Graça (2013), envolve várias circunstâncias que afetam tanto as características intrínsecas como as extrínsecas da sala de aula. O ambiente de sala de aula pode ser promissor ou amedrontador para o estudante, em relação aos conhecimentos produzidos nas disciplinas e que demarcam o início da carreira. A base teórica de investigação da carreira docente apresenta um alargado conjunto formado por ciclos, fases ou etapas que explicam como o indivíduo se torna professor. Estudos sobre o início da carreira (HUBERMAN, 2000; FARIAS; NASCIMENTO, 2012; BOTH, 2016; CONCEIÇÃO; MOLINA NETO, 2016; ILHA; KRUG, 2016; WITTIZORECKI; FRASSON, 2016) revelam que essa fase curta instiga preocupação nos cursos de formação inicial, requerendo que fatores da vida profissional sejam tematizados e amplamente discutidos, visando à futura intervenção. Na intervenção pedagógica do professor de Educação Física iniciante, os conhecimentos adquiridos durante a formação inicial são potencializados dia após dia, no constructo de uma carreira permeada por avanços que delineiam a trajetória docente.

\section{Considerações finais}

Ao final do estudo, apurou-se que as investigações sobre o início da carreira docente ainda são escassas na literatura, considerando-se o reduzido número de publicações encontradas. Ressalva-se, no entanto, que o período abrangido pela busca dos dados pode ter sido uma limitação do estudo. Não obstante, emerge a necessidade de a comunidade científica direcionar mais investigações para essa temática, associada a diferentes realidades e variáveis.

Evidenciou-se que a coleta das informações dos estudos com professores iniciantes na carreira docente foi efetivada com base em questionários e entrevistas. Não foram encontrados estudos realizados nas regiões Norte, Nordeste e Centro-Oeste, centrando-se as investigações nos estados do Sul e do Sudeste.

Pode-se perceber, a partir das evidências apresentadas nos estudos elencados, que o perfil dos professores no início de carreira está relacionado com as expectativas profissionais, voltadas para o âmbito financeiro e social, sobressaindo-se as expectativas pessoais, de 
satisfação e prestígio. No entanto, para compor um perfil dessa população, necessita-se de maior robustez de evidências.

Independentemente de estarem os professores no início da carreira ou em fases mais avançadas, a insatisfação salarial é um dos aspectos que se destacam, sendo ressaltado pelos professores iniciantes. Outro aspecto relevante são as experiências do momento de entrada e do processo de início da carreira que influenciam diretamente a maneira como o docente organiza sua prática pedagógica. Ao final deste estudo, considera-se que o tema em questão carece de mais investigações, devido à sua relevância para melhor conhecimento das situações inerentes ao início da carreira docente.

\section{Referências}

ALVES, F. O encontro com a realidade docente: ser professor principiante. Lisboa: Instituto de Inovação Educacional. 2001

AMORIM FILHO, M. L.; RAMOS, G. N. S. Trajetória de vida e construção dos saberes de professoras de educação física. Revista Brasileira de Educação Física e Esporte, São Paulo, v. 24, n. 2, 2010.

ANTUNES, F. H. C. et al. Um retrato da pesquisa brasileira em Educação Física escolar: 1999 - 2003. Motriz, Rio Claro, v. 11, n. 3, p. 179-184, set./dez. 2005.

BARDIN, L. Análise de conteúdo. Lisboa: Edições 70, 1977.

BOTH, J. Bem-estar do trabalhador docente de Educação Física no início da carreira: síntese das investigações. IN: CONCEIÇÃO, V. J. S.; FRASON, J. S. (Org.). Textos e contextos sobre o trabalho do professor de Educação Física no início da docência. Porto Alegre: Editora Sulina, 2016. p. 85-109.

BOTH, J. et al. Bem-estar do trabalhador docente em educação física ao longo da carreira. Journal of Physical Education, Maringá, v. 24, n. 2, p. 233-246. 2013.

BRASIL. Resolução $n^{\circ} 2$, de $1^{\circ}$ de julho de 2015. Define as Diretrizes Curriculares Nacionais para a formação inicial em nível superior (cursos de licenciatura, cursos de formação pedagógica para graduados e cursos de segunda licenciatura) e para a formação continuada.

CARDOSO, V. D.; VOLPATO, G. Programas de mentoria para professores iniciantes: conceitos, características, e importância em diferentes contextos. In: CONCEIÇÃO, V. J. S.; FRASON, J. S. (Org). Textos e contextos sobre o trabalho do professor de Educação Física no início da docência. Porto Alegre: Editora Sulina, 2016. p. 129-147.

CAVACO, M. H. Ofício do professor: o tempo e as mudanças. Porto: Porto Editora, 1991.

CONCEIÇÃO, V. J. S; MOLINA NETO, V. Formação e prática educativa do professor de educação física: início da docência sob olhar da pedagógica crítica. In: CONCEIÇÃO, V. J. S.; FRASON, J. S. (Org.). Textos e contextos sobre o trabalho do professor de Educação Física no início da docência. Porto Alegre: Editora Sulina, 2016. p. 23-44. 
COUTINHO, R. X. et al. Análise da produção de conhecimento da Educação Física brasileira sobre o cotidiano escolar. Revista Brasileira de Pós-Graduação, Brasília, v. 9, n. 17, p. 491516, jul. 2012.

FARIAS, G. O. et al. A identidade profissional de professores de educação física no início da carreira. In: CONCEIÇÃO, V. J. S.; FRASON, J. S. (Org.). Textos e contextos sobre o trabalho do professor de educação física no início da docência. Porto Alegre: Sulina, 2016. p. 205- 225 .

et al. Carreira docente em educação física: uma abordagem sobre a qualidade de vida no trabalho de professores da rede estadual de ensino do Rio Grande do Sul. Journal of Physical Education, Maringá, v. 19, n. 1, p. 11-22, 1. trim. 2008.

. et al. Competências profissionais em Educação Física: uma abordagem ao longo da carreira docente. Motriz, Rio Claro, v. 18 n. 4, p. 656-666, out./dez. 2012.

. et al. Crenças e expectativas constituídas ao longo da carreira docente em educação física. Journal of Physical Education, Maringá, v. 22, n. 4, p. 497-509, 2011.

et al. A identidade profissional de professores de educação física no início da carreira. In: CONCEIÇÃO, V. J. S.; FRASON, J. S. (Org.). Textos e contextos sobre o trabalho do professor de Educação Física no início da docência. Porto Alegre: Editora Sulina, 2016.p. 205-225.

;NASCIMENTO, J. V. Fatores intervenientes na carreira docente de professores de Educação física. Pensar e Prática, Goiânia, v. 15, p. 465-483, 2012.

FOLLE, A. et al. Construção da carreira docente em Educação Física: escolhas, trajetórias e perspectivas. Movimento, Porto Alegre, v. 15, p. 25-49, jan./mar. 2009.

FREIRE, L. I. F.; FERNANDEZ, C. O professor universitário novato: tensões, dilemas e aprendizados no início da carreira docente. Ciência \& Educação, Bauru, v. 21, n. 1, p. 255272, 2015.

FREITAS, M. N. C. Organização escolar e socialização profissional de professores iniciantes. Cadernos de Pesquisa, São Paulo, n. 115, p. 155-172, mar. 2002.

GABARDO, C. V.; HOBOLD, M. S. Início da docência: investigando professores do ensino fundamental. Revista Brasileira de Pesquisa sobre Formação de Professores, Belo Horizonte, v. 3, n. 5, p. 85-97, ago./dez. 2011.

GARCIA, C. M. Formação de professores: para uma mudança educativa. Porto: Porto Editora, 1999.

GONÇALVES, E. C. F.; SANTOS, A. E. O.; MARTINS JÚNIOR, J. A. Prática docente: dificuldades encontradas pelos professores de Educação Física nos cinco primeiros anos de atuação profissional. O Mundo da Saúde, São Paulo, out./dez. 2007.

GONÇALVES, J. A. M. A carreira das professoras do ensino primário. In: NÓVOA, A. (Org.). Vidas de professores. 2. ed. Porto: Porto Editora, 2000. p. 141-170. 
Desenvolvimento profissional e carreira docente: fases da carreira, currículo e supervisão. Sísifo, Lisboa, n. 8, p. 23-36, jan. /abr. 2009.

HUBERMAN, M. O ciclo de vida profissional dos professores. In: NÓVOA, A. (Org.). Vidas de professores. Porto: Porto Editora, 2000. p.31-62.

ILHA, F. R. S.; KRUG, H. N. O professor iniciante e a educação física escolar: desafios que se soma. In: CONCEIÇÃO, V. J. S.; FRASON, J. S. (Org.). Textos e contextos sobre o trabalho do professor de Educação Física no início da docência. Porto Alegre: Editora Sulina, 2016. p. 181-204.

LEITE, B. D. et al. Profile of the researchers with productivity grants in the Brazilian National Research Council (CNPq) of the Physical Education Area. Motriz, Vila Real, v. 8, n. 3, p. 90-98, jul. 2012.

MARCON, D., NASCIMENTO, J. V., GRAÇA, A. B. S. O conhecimento do contexto na formação inicial em Educação Física. Revista Brasileira de Educação Física e Esporte, São Paulo, v. 27, n. 4, p. 633-45, out./dez. 2013.

MARTINS, R. G. L. Bem-estar do trabalhador docente em Educação Física da Região de Jataí - Goiás. 2016. 186 f. Dissertação (Mestrado em Educação Física) - Programa de PósGraduação Associado em Educação Física, Universidade Estadual de Londrina/Universidade Estadual de Maringá, Londrina/Maringá, 2016.

MOREIRA, H. R. et al. Qualidade de vida no trabalho e perfil do estilo de vida individual de professores de Educação Física ao longo da carreira docente. Motriz, Rio Claro, v.16, n.4, p. 900-912, out./dez. 2010.

NEGRINI, A. Instrumento de coleta de informações na pesquisa qualitativa. In: MOLINA NETO, V.; TRIVIÑOS, A. N. S. (Org.). A pesquisa qualitativa na Educação Física: alternativas metodológicas. Porto Alegre: Sulina, 2010. p. 61-99.

ROSSI, F.; HUNGER, D. As etapas da carreira docente e o processo de formação continuada de professores de Educação Física. Revista Brasileira de Educação Física e Esporte, São Paulo, v. 26, n. 2, p. 323-338, 2012.

SAMPAIO, R. F.; MANCINI, M. C. Estudos de revisão sistemática: um guia para síntese criteriosa da evidência científica. Brazilian Journal of Physical Therapy, São Carlos, v. 11, n. 1, p. 83-89, jan./fev. 2007.

SANTOS, S. G.; MORETTI-PIRES R. O. (Org.). Métodos e técnicas de pesquisa qualitativa aplicada a Educação Física. Florianópolis: Tribo da Ilha, 2012.

SAUR-AMARAL, I. Revisão sistemática da literatura com apoio de Endnote X4 e NVIVO 9. Aveiro: GOVCOPP, 2011.

SCHÜTZ, G. R.; SANT'ANA, A. S. S.; SANTOS, S. G. Política de periódicos nacionais em Educação Física para estudos de revisão sistemática. Revista Brasileira de Cineantropometria e Desempenho Humano, Florianópolis, v. 13, n. 4, p. 313-319, 2011. 
SILVA, C. L.; VELOZO, E. L.; RODRIGUES JUNIOR, J. C. Pesquisa qualitativa em educação física: possibilidades de construção de conhecimento a partir do referencial cultural. Educação em Revista, Belo Horizonte, n. 48, p. 37-60, dez. 2008.

STEFFY, B. E. et al. The model and its application. In: STEFFY, B. E. et al. (Org.). Life cycle of the career teacher. California: Kappa Delta Pi, 2000. p. 1- 25.

WITTIZORECKI, E. S.; FRASSON, J. S. Professores iniciantes: do choque do real ao encontro com a docência. In: CONCEIÇÃO, V. J. S.; FRASON, J. S. (Org.). Textos e contextos sobre o trabalho do professor de Educação Física no início da docência. Porto Alegre: Editora Sulina, 2016. p. 227-242.

Recebido em: 21/03/2017

Revisado em: 23/08/2017

Aprovado em: 21/11/2017

Endereço para correspondência:

arouca.neto@hotmail.com

Adair João Rachadel Arouca

Universidade do Estado de Santa Catarina, Florianópolis

Av. Me. Benvenuta, 2007- Itacorubi

88035-901- Florianópolis, SC -Brasil 